\title{
ROBERT C. KNAPP, ROMAN INSCRIPTIONS OF CENTRAL SPAIN
}

\author{
P()R \\ EMILIO RODRIGUEZ ALMEIDA \\ Escuela Española de Historia y Aryueologia del C.S.I.C., Roma
}

\begin{abstract}
RESUMEN
Comentario a la reciente seric epigráfica del material romano de las provincias de Avila, Segovia y Madrid. con destino al nuevo $C I I . I I$, de Robert C. Knapp.
\end{abstract}

\section{SUMMARY}

Artical-review to the R. C. Knapp new epigraphical monography of the inscriptions of Avila. Segovia and Madrid. written with the final destination to the new $(I L / I$.

En la última década, la epigrafia hispánica ha vuelto a ponerse de gran actualidad con el descubrimiento de nuevos y fundamentales documentos de carácter público (como las leges broncineas Contrebiensis e Irnitana, o como la Tabula Siarensis. por citar sólo los ejemplos más conocidos). Pero ésta es una Hispania del todo diversa de la de la meseta central donde faltan hasta ahora documentos epigráficos de peso semejante, mientras abundan los ajados restos de una epigrafia "pobre», rural, descentrada respecto a los grandes núcleos urbanos del poder, de la administración o de los negocios. No maravilla, por tanto, el hecho de que los cultores de este tipo de estudios hayan sido en el pasado más bien pocos y modestos. Es verdad que el alba de nuestro siglo ha visto afanarse en este campo un $P$. Fita (entre los autóctonos) y un E. Hübner (entre los "enamorados forasteros"); pero hemos de pasar la mitad de la centuria para ver, entre mil tentativas sectoriales, tomar cuerpo el trabajo de los varios

\footnotetext{
'Berkeley, Ca. California University Press. Classical Studies 34. 1992, 8., 476 páginas, 66 tablas y microfichas.
}

Serrano Gallego, Hurtado S. Antonio. Rubio Alija, Mangas y, sobre todo, el fundamental aporte de M. L. Albertos. En los años setenta, otro eloving foreigner», G. Alföldy, con un ambicioso proyecto de reedición del $C I L I I$, reengancha definitivamente a la corriente «mitteleuropea» esta parcela geográfica de la epigrafĩa clásica.

En la linea de estos estudios y en la horma de Alföldy se encuadra la investigación de R. C. Knapp' Otros trabajos suyos lo habian calificado precedentemente como observador atento de fenómenos y experiencias de la arqueologia y de la historia hispanicas (Aspects of the Roman experience in theria: 206 B. C.-100 B.C., Valladolid, 1977; The origins of provincial prosopography in the West, in Ancient Society 9, 1978, 187-222; Roman Cordoba: Berkeley, 1983) y habiamos tenido ocasión de conocerlo como un riguroso, solícito y agudo observador de muchos aspectos de nuestra arqueologia y de nuestra epigrafia. Sus prospecciones (a la búsqueda de materiales epigraficos) en las provincias de Avila y Segovia me dieron el especial privilegio. en los primeros años ochenta, de conocer personalmente (con inmenso beneficio) no sólo al investigador serio, riguroso y profundo, sino también al hombre mesurado, al compañero jovial y premuroso, al amigo fraterno. Esta deuda personal crece ahora con el cuidado y atención que pone en subrayar incluso mis minimas contribuciones a su última monumental obra. Estas pocas lineas quieren ser expresión sincera de mi aprecio y de mi afecto. Latin inscriptions of Central Spain es una obra para la cual no es dificil prever el grandisimo éxito que obtienen de derecho las obras imprescindibles, siendo la primera grande, sistemática y completa serie de inscripcio- 
nes de una zona mas bien vasta y poco investigada de la Meseta y un sillar importante de la construcción del nuevo ( $/ 1$. I/ que esta en puertas.

La obra esta concebida substancialmente en dos partes desigualmente extensas, una de recopilación y lectura de documentos (páginas 3-309, con algunos apendices, p. 311-337) y una serie de estudios dedicados a los problemas que están en la base de la exégesis epigrafica o constituyen su natural corolario: paleografia, onomástica, datos socio-ambientales (familia, demografia, status social, administración, ejército, movimientos interétnicos, etc.). Haremos solamente algunas anotaciones sobre cada una de estas dos partes en que el trabajo aparece dividido.

\section{LA SERIE EPIGRÁFICA}

La serie de documentos epigráficos está reunida en grupos de unidades geográficas, en cuyos centros se encuentran Avila y Segovia para las respectivas provincias y Alcalá de Henares para la de Madrid (Madrid misma, en cuanto localidad antigua, resulta, por los materiales allí recogidos, insignificante). Los epigrafes aparecen fichados individualmente, comenzando por los de carácter sacro u honorifico (unos 40 en total); pero «la parte del león» la obtiene, como siempre, la epigrafia funeraria. Al instrumentum domesticum pertenece una sola (n. 331), un dato que proporciona la medida de cuánto aún resta por investigar y recoger en los museos y colecciones de todo tipo de la región. El resultado, de todos modos, es un número altísimo ( $\mathrm{y}$ hasta ahora casi inimaginable) de 331 epígrafes: tantos, si se tiene en cuenta el carácter aislado y moralmente "periférico" (por usar un término a la vez paradójico y eficaz) respecto a la Hispania levantina y meridional. Estamos, en efecto, en esa especie de «limbo" de la Meseta Duero-Tajo, en los confines poco accesibles de los conventus Tarraconenses de Clunia y Carthago Nova y el lusitano de Emerita Augusta. Las fichas se inician con una descripción sumaria y todas las noticias (sintéticas) antiguas y modernas relativas a cada pieza; sigue la transcripción según los habituales y más aceptados criterios epigráficos; se continúa con las referencias bibliográficas (igualmente sintéticas); se termina con una discusión breve de los datos obtenidos de la transcripción y lectura, y con eventuales confrontaciones con otros epígrafes.

No nos detendremos excesivamente en el análisis de los grupos zonales (Avila, Madrid, Segovia), de los que los dos últimos nos son (al menos directamente) desconocidos, limitándonos (por razones, sobre todo, practicas) a pocos comentarios sobre algunos aspectos generales del trabajo, cuya mole y cuya precisión dejan poco espacio tanto a la crítica cuanto, sobre todo, a las mejorias, y que, si bien tendra en un futuro necesidad de puesta al dia, dificilmente podrá considerarse metodológicamente superado. Las pocas reservas que expresamos sobre algunos aspectos (marginales, sobre todo) estoy seguro que no serán desdenadas por la seriedad del investigador y por la benevolencia del amigo.

Probablemente poco quita, pero ciertamente nada añade al magnifico carácter metodológico del catálogo epigráfico, la serie de dibujos a línea que acompaña pieza a pieza (cuando éstas se conservan y son visibles, o, al menos, conocidas por reproducción fidedigna) las fichas individuales. Junto a una abundante dotación de 24 tablas y 42 microfichas fotográficas, estos dibujos (obra de A. Futrell, que firma en sigla cada pieza) desentonan un poco, porque "traicionan" en algún modo el rigor y la atención que el autor ha puesto a manos llenas en el texto. De casi todos los dibujos (pero especialmente de algunos como los de las fichas $n^{\circ} 49,123,135,176$, $179,181,205,211$, etc.) se deduce con claridad que han sido realizados a partir de una base fotográfica $o$ de dibujo pre-existente. Ahora bien, si este procedimiento es comprensible (e incluso, a veces, inevitable) en el caso de piezas hoy perdidas o dificilmente observables por las más diversas razones (como la altura en que a veces se encuentran ciertos epigrafes de la muralla de Avila), no lo es para la mayoria de las piezas. La fotografia es una excelente base de información visual complementaria; la buena regla pretende que tal sea siempre, y que si de ella se obtiene una primera versión "depurada» del epigrafe (eliminando eventualmente sombras y otros elementos de alteración), tal versión sea sucesivamente controlada con atención in conspectu lapidis. Más aún, las mejores versiones gráficas se obtienen (cuando la operación es materialmente posible) a través de calcos (cartáceos o de otro tipo) «depurados» del mismo modo que las versiones fotográficas. Por atenernos al campo que conozco más directamente, algunos epigrafes abulenses como los números $4,29,32,39,44 / 45$ y 47 , si se comparan no ya con los originales, sino con el mismo material fotográfico auxiliar, resultan, sí, claros, pero de poca confianza. Me limitaré a tres ejemplos en que tales dibujos parecen haber influido negativamente en el desarrollo de la ficha correspondiente.

En el $n^{\circ} 2$, encontramos el dibujo de un arula con dedicación sacra, dotada de tres estrechas bandas en relieve en lo alto, pero sin pulvini laterales; la pieza es levemente troncopiramidal. Yo la había 
publicado antes (.4vila Romana. Avila. 1981. p. 174. $\mathrm{n}^{\prime \prime} 98$ ), ilustrándola con un pequeño dibujo obtenido directamente ( $\sin$ intermediario fotográfico), donde aparece perfectamente prismática y con dos pulvimi regularisimos en lo alto. En la misma lámina aparecia una versión gráfica de la página epigráfica obtenida directamente por calco "cartáceo", realizado personalmente en los locales del Museo de Bellas Artes de Avila (anejo de la ex-iglesia de Sto. Tomé) con la ayuda del mismo R. Knapp. De tal calco sc obtenia claramente la lectura Maiduanae/Naimpis (o Animpis, Anvmpis)/Minerves. Con todas las reservas que la excepcionalidad de la pieza en Avila (la única sacra, la única en un tipo de piedra aparentemente no local) puede plantear, resulta dificil, sin embargo, entender por qué razón en la ficha de Knapp no se haya tenido en cuenta el calco "cartáceo», sea para la ilustración de la pieza, sea para su lectura. en la cual se pretende leer (última linea) un, en mi opinión, inexistente $v$ (otum) s(olvit) l(ihens) m(erito): la cosa puede ser imputable, creo, sólo a un negativo (pero decisivo) influjo del dibujo en cuestión. obtenido de una fotografia tan poco clara que ha hecho desaparecer incluso los pulvini de la parte alta.

En el $n^{\circ} 47$, encontramos un consumidisimo fragmento de granito que, colocado en la muralla de Avila a notable altura, no es fácilmente observable a simple vista.

Mi familiaridad con ésta, como con el resto de las inscripciones de Avila, se remonta al lejano 1952. cuando comenzaba a ocuparme "diletantísticamente" de estos materiales. Desde entonces, al menos, una decena de observaciones y otras tantas versiones gráficas y fotográficas me habian dado la relativa seguridad de una lectura.../Nerba[e]/Trai(ani) Caes(aris)/ serbi. En la misma foto de Knapp (tab. 28 y nuestra fig. 2), al menos en la última linea, aparece perfectamente legible serbi; pero en la transcripción resulta una cosa enteramente diversa y en el comentario se añade: "I do not know how his (i. e., E.R.A.) readings are possible». Pues bien, aparte la intrínseca dificultad de la erosionadisima pieza, creo que la experiencia de al menos dos decenios de contacto casi diario ofrezca la garantía, si no de interpretar, al menos de ver con mayor seguridad lo poco que es visible.

En fin, el tercer ejemplo, el $n^{\circ} 48$, encontramos otro dibujo claramente obtenido de fotografia y una restitución gráfica evidentemente incompleta. Por ejemplo, aparecen (y se transcriben) cuatro líneas de escritura y se da como leída por mi, «pero no observable en la piedran, la fórmula final f(aciendum) $c$ (uravit). Pues bien, ya la simple fotografía por $\mathrm{mi}$ publicada en $A . R ., \mathrm{n}^{\circ} 17$, p. 112 , evidencia absoluta
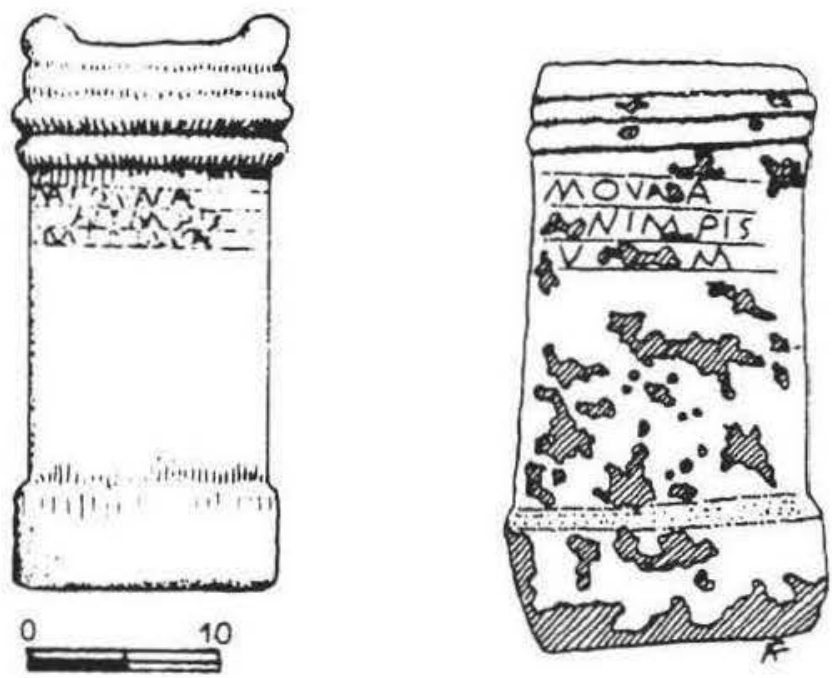

AR 98

LICS 2

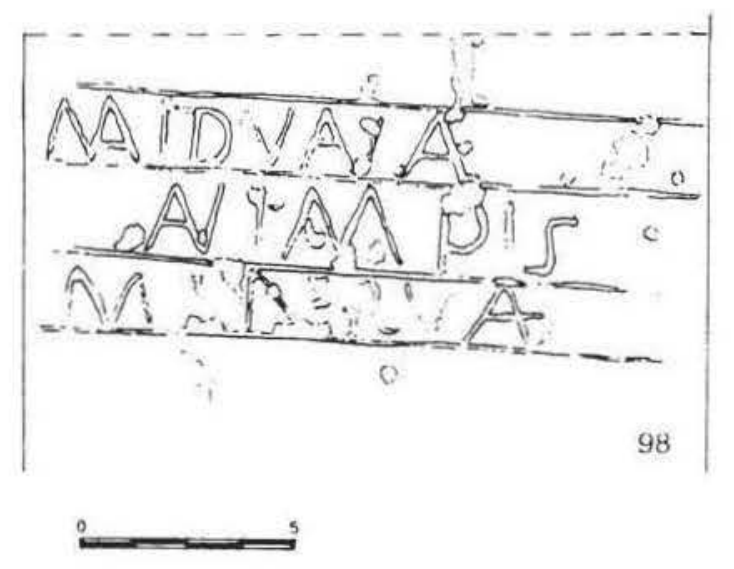

Figura I. La inscripción Knapp 2, de Avila: a) versión gráfica Rodriguez Almeida, 1981: h) versión LICS, y c ) copia, obtenida por ealco cartáceo, de la página epigráfica.

e indiscutiblemente la presencia de la quinta linea con tal fórmula; en el momento de la redacción final de la ficha de Knapp, la fotografia, evidentemente, no ha sido controlada. Si en la foto de Knapp tal linea no es visible (tabla 28 ), la razón es que, cuando se ha realizado la instantánea, la tierra (porque la pieza se encuentra al nivel del suelo) cubria la última linea. Véase fig. 3.

De todo esto nace una reflexión. Es verdad que la palabra escrita suple, al menos en general, a la escasa claridad de ciertos documentos epigráficos; pero es verdad igualmente que, a veces, una imagen vale mil palabras y deja a quien la contempla más libertad de juicio que una sentencia escrita. Si en homenaje al método somos puntillosamente fieles en no descuidar ningún tipo de referencia bibliográ- 


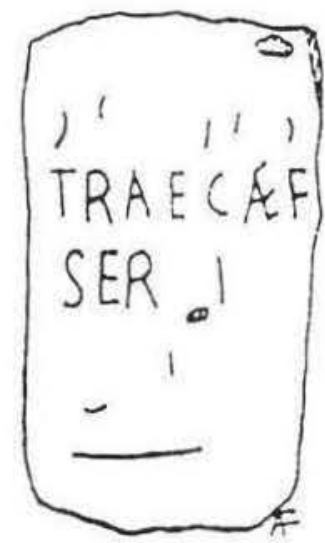

LICS 47

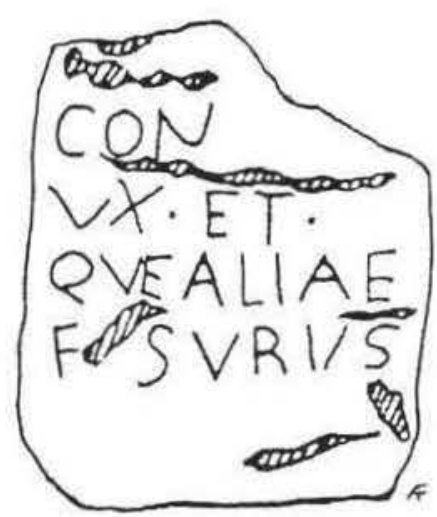

AR 17
37

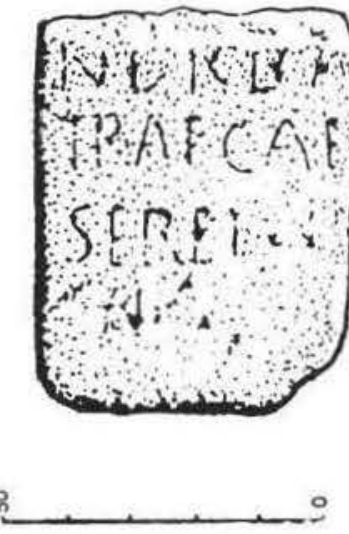

Figura 2.-La inscripción Knapp 47; $a$ ) versión gráfica LICS 47: b) versión gráfica R. A. 1981; y c) relativa fotografia (obtenida con teleobjetivo).

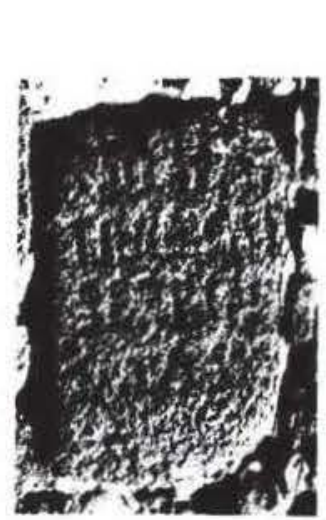

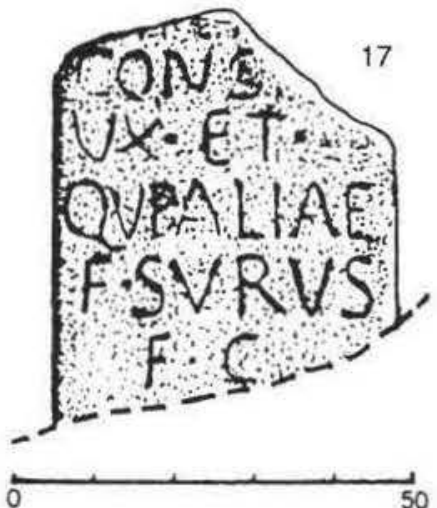

50

0
AR 37

Figura 3.- La inscripción Knapp 48: a) versión gráfica LICS $48 ; b \mathrm{y} c$ ) versión gráfica y relativa fotografia $\mathrm{R}$. A. 1981. fica, ¿por qué no reservar a las imágenes obtenidas precedentemente a nuestro examen el mismo reverente trato, al menos en aquellos casos en que un juicio definitivo es dificil o imposible? Como para la escultura o la gran epigrafia rebuscamos en los fondos de nuestras fototecas a la búsqueda de imágenes "oficiales» (casi siempre de repertorio y conocidas rutinariamente a través de mil publicaciones), ¿.por qué razón, en el caso de la epigrafia "pobre», no usar imágenes que otros ojos y otras manos (tal vez en mejores condiciones ambientales o de luz, o a través de mayor familiaridad con el objeto) han obtenido con no menos esfuezo del nuestro? Se puede responder, no sin razón: «Se corre el riesgo de agravar (incluso económicamente) la publicación». Es cierto; pero los trabajos de gran importancia y de gran rigor, como éste, no deben ser privados de elementos de juicio que pueden resultar preciosos.

\section{MATERIALES SUPLEMENTARIOS (págs. 313-338).}

En el apéndice E. («post-classical inscriptions») figura con el numeral I una ficha sobre «an extensive graffito...carefully carved on a block of granite in the Southern corner of the Western wall of the church of S. Pedro..., just outside the Eastern wall of Avila». Se considera esta inscripción (justamente) moderna ( (sixteenth to eighteenth century?») y se da la transcripción «Haz luego lo [que]/ quisieras (h)aver $\mathrm{h}[\mathrm{e} / \mathrm{cho}] / \mathrm{a}[\mathrm{ti}]$ ", poniéndola en relación con los textos evangélicos Matt., 7.12 y Luc., 6.31 que, sintéticamente, son una invitación a "hacer a los otros lo que quisiéramos que se hiciese a nosotros mismos». Ha pasado inadvertido a Knapp el sentido clásico (pre-renacentista) del adverbio «luego" (ahora, inmediatamente), que cambia completamente el sen- 
tido del texto. En efecto, su colocación en el area cementerial antigua de la iglesia significa que la inscripción aconseja pensar en el "más allà, y la restitucion debe hacerse en la forma siguiente: "Ha/ hoy lo [que]/ quisieras (h)aver h[echo] alyer]".

En el mismo apéndice. $n^{\circ}$ XIV, una inscripción muy notable de Fuentidueña. Segovia, descubierta en 1985 , con texto tardolatino titubeante, da no pocos problemas al epigrafista y al intérprete. R. Knapp

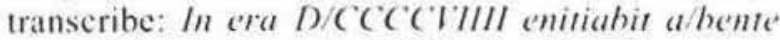
pro(e)s(hy)te(ro))/s(an)c(l)i Mi (c)hac/(is)e interpreta: "In the Spanish era 909 (this building) was consacrated by the blessed presbyter of St. Micheln, dando a entender (tal vez involuntariamente) que el "edificio" en cuestión sea diverso de la iglesia de $\mathrm{S}$. Miguel. Más tarde, al final del comentario, leemos, sin embargo, que la piedra «probably commemorates the construction of the first church to be built after the reconquest». Ahora bien, que la iglesia haya sido construida de nuevo en el 871 , en el reinado de Alfonso III el Grande de León, es, como mínimo, dudoso. Knapp supone que enitiahit esté por enitiabit(ur) (que seria error del lapicida, por enitiahatur): yo creo, en cambio, que es un pretérito perfectamente regular enitiahit (initiavit); ahente presbytero es un pseudo-ablativo, por habens, con el sentido de «a tener". Falta la expresión ecclesia, pero seguramente no era necesaria, ya que la piedra estaba fijada en su entrada. De modo que el sentido de la inscripción es perfectamente claro: «En la era 909 (año 871) (fue abierta al culto y) comenzó a tener cura (esta iglesia de) S. Miguel»).

Todo esto da lugar a las siguientes consideraciones: $a$ ) la piedra no habla (al menos expresamente) de "construcción» de la iglesia, sino de «apertura al culton y de la titularidad de un párroco; $b$ ) por tanto. probablemente la iglesia existía precedentemente; c) no podia ser más que la iglesia visigótica de la comunidad precedente a la invasión mora, un siglo y medio antes; $d$ ) es posible que la comunidad mora no la haya transformado en mezquita, asegurando de tal modo la supervivencia de la estructura; en todo caso, en el año 871 , mucho antes de que la reconquista "oficial» asegure a Castilla-León estos parajes, una comunidad de pioneros ha ocupado el lugar y restituido al culto la iglesia, restableciendo el clero local: un fenómeno hasta ahora poco documentado.

\section{FSTUDIOS (OMPLEMENTARIOS}

(pigs. 339-376)

La primera de estas secciones está dedicada a tra/ar un encuadramiento cronológico de una epigrafia en si misma extremadamente pobre de dataciones intrinsecas ciertas (apenas 7. de los años 128 . 179. 191.200 .224 .265 y 339 d.C.). Fis un esfuer/o que puede hacer temblar a tantos especialistas. pero que R. Knapp afronta con tanta decisión como prudencia sobre una amplia base de parametros: formas nominales, cronologia comunmente aceptada de ciertos nombres, historia y geografia comparada de otros (gentilicios y cognomina), procedencia de la población móvil, fórmulas funerarias, superlativos de afecto (carissimus, piissimus, etc.) y, en fin, paleografia en sus diversos aspectos (formas literales, interpunciones, ordinatio impaginatio, contignationex. division de palabras en diversas lineas, etc.). Con la reserva explicita que ueven in the best of circumstances, dating to closser than 50-100 year periods is impossible" (p. 382), las conclusiones (págs. 283-284) dan para la mayor parte de estas inscripciones un espectro cronológico a cuyos extremos se encuentran de una parte la edad flavio-trajanea y, de la otra, la mitad del siglo it de nuestra era.

El trabajo termina egregiamente con una serie de estudios estadísticos relativos a la vida familiar (págs. 385-395), otros datos demográficos (págs. 396399), status social (pags, 400-404), vida religiosa (págs. 405-407), forasteros y población móvil (págs. 408-411) y, en fin. ejército y administración pública (págs. 412-413).

Como se ve, el material y su estudio ofrecen la mies de datos que tantos especialistas de las disciplinas históricas tienen que manejar continúamente y que no siempre son disponibles, especialmente para zonas como ésta. La información contenida en el trabajo es no sólo abundante, sino metodológicamente sólida y bien fundada. Frente al enorme cúmulo de materia y de doctrina, las mínimas pecas a que nos hemos referido son insignificantes peccata minuta en un opus bene inceptum, optime absolutum. del que epigrafistas, prosopógrafos e historiadores de la peninsula ibérica no podrán, en el futuro, prescindir en sus trabajos. 